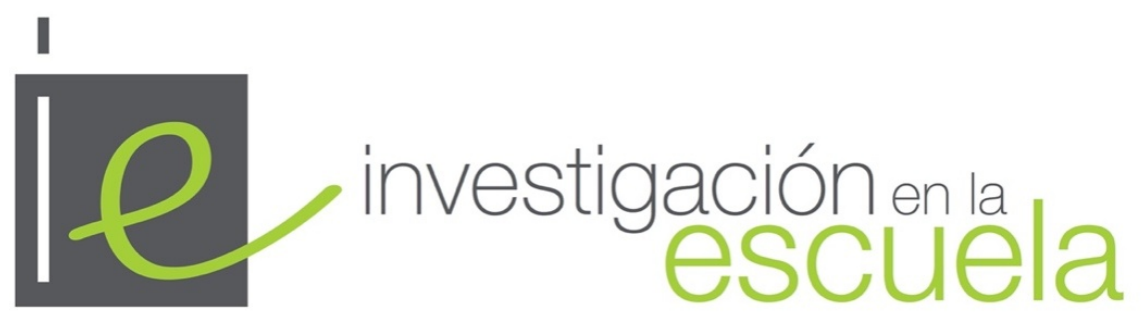

Revista de Investigación e Innovación Educativa nº 101, 2020 | e-ISSN 2443-9991

\title{
Desarrollo de competencias docentes en educación patrimonial mediante plataformas 2.0 y entornos digitales como herramienta de aprendizaje
}

\author{
Development of teaching skills in heritage education through 2.0 platforms and digital environments as a learning \\ tool
}

iD Dra. Olaia Fontal Merilla es Profesora Titular en la Facultad de Educación y Trabajo Social de la Universidad de Valladolid (España)·olaia.fontal@uva.es https://orcid.org/0000-0003-1216-3475

iD Dra. Silvia García-Ceballos es Profesora Ayudante Doctora en la Facultad de Educación de la Universidad de Zaragoza (España)·sgceballos@unizar.es https://orcid.org/0000-0002-7661-3001

iD Lic. Borja Aso Morán es Profesor Asociado en la Facultad de Educación de la Universidad de Zaragoza (España) ·basom@unizar.es https://orcid.org/0000-0002-3023-4516

Resumen. El desarrollo de competencias docentes en educación patrimonial ha de estar presente en los grados formativos de los futuros docentes. Este artículo presenta una investigación estructurada en dos fases, realizada a 132 alumnos de $2^{\circ}$ grado de educación primaria: un estudio exploratorio sobre la presencia del patrimonio en las etapas educativas previas a la formación universitaria, y un estudio comparativo pretest-postest que analiza la transformación conceptual que se produce en la noción de patrimonio antes y después de trabajar la educación patrimonial mediante el uso de plataformas 2.0 y entornos digitales. La revisión teórica nos lleva a definir una propuesta pionera de competencias docentes en educación patrimonial y los principales resultados del estudio indican que: (a) los alumnos poseen una noción inicial reduccionista del patrimonio, (b) tras la implementación educativa el concepto orbita hacia una definición integral y humanista, y (c) las reconceptualizaciones integran valores, usos y aportaciones del patrimonio, además de mostrar compromiso y responsabilidad con el legado cultural.

\begin{abstract}
The development of teaching skills in heritage education must be present in the training degrees of future teachers. This article presents a research structured in two phases, carried out to 132 students of 2nd grade of primary education: an exploratory study on the presence of heritage in the educational stages prior to university education, and a comparative pretest-posttest study that analyzes the conceptual transformation that occurs in the notion of heritage before and after working heritage education through the use of 2.0 platforms and digital environments. The theoretical review leads us to define a pioneering proposal of teaching competences in heritage education and the main results of the study indicate that: (a) students have an initial reductionist notion of heritage, (b) after educational implementation the concept orbits towards a comprehensive and humanistic definition, and (c) reconceptualizations integrate values, uses and contributions of heritage, in addition to showing commitment and responsibility with the cultural legacy.
\end{abstract}

\section{Palabras clave $\cdot$ Keywords}

Educación patrimonial, patrimonio cultural, educación primaria, competencias docentes, plataformas 2.0, TIC. Heritage education, cultural heritage, primary education, Teaching skills, 2.0 platforms, ICT.

\section{Introducción}

El vertiginoso avance de las Tecnologías de la Información y la Comunicación dota al patrimonio de nuevos contextos de aprendizaje, favoreciendo su accesibilidad y ampliando las formas de acercamiento e 
interactuación con él. En este sentido, el universo digital se ha convertido en un espacio de primer orden en relación con la Educación Patrimonial (Piñeiro-Naval et al., 2018), ya que en este entorno virtual se generan variados procesos de conocimiento, comprensión, puesta en valor, sensibilización y disfrute del patrimonio cultural, lo que sitúa internet como un espacio identitario en un contexto internacional (Feldman, 2017; Chng \& Narayanan, 2017).

Por otra parte, desde la práctica docente se ha ido incrementando el trabajo en entornos 2.0 , utilizando estas plataformas como medio de acercamiento y conocimiento del patrimonio, además de como medio de experimentación, creación, coconstrucción de conocimientos y de difusión de proyectos patrimoniales. La integración de las plataformas y entornos 2.0 nos permite acercar el patrimonio y desarrollar en el alumnado la competencia digital (tan necesaria en el siglo XXI), mediante un enfoque indagador y constructivo a través de las múltiples posibilidades que nos ofrece la red.

Sin embargo, tanto la educación patrimonial como el empleo de soportes virtuales tienen que responder a una enseñanza basada en competencias (docentes). La inclusión de las competencias en el sistema educativo por parte del Consejo de Europa (2006) ha supuesto un cambio sustancial en la concepción de la formación. En relación con el término "competencia(s) docente(s)", existe una amplia producción científica que pone de relieve la diversidad de definiciones y categorizaciones realizadas, entre las que destacamos a Perrenoud (2005), autor referente, y el estudio de Tejada (2009) que recopila algunas de ellas (Zabalza, 2003; Valcárcel, 2005; Pérez, 2005; Ayala, 2008) y propone una categorización propia. Por otra parte, autores como Cano (2005), Perrenoud (2005), Cañadas et al. (2019) definen el concepto "competencias docentes". Sin embargo, estas categorizaciones se alejan de nuestra práctica educativa si lo que queremos es proponer competencias docentes específicas para trabajar la educación patrimonial de manera óptima, por ello se vuelve necesario concretarlas en otras más específicas realmente operativas.

El presente estudio recoge una propuesta de competencias docentes, partiendo de los modelos teóricos ya existentes, que cualquier educador y profesional del patrimonio debe desarrollar en su formación. Estas competencias se establecen en relación a la arquitectura didáctica definida por Fontal (2003), que sustenta nuestra metodología educativa y evaluativa en la formación de docentes. Bajo estos pilares se implementa un bloque temático de educación patrimonial a estudiantes de $2^{\circ}$ curso de grado de educación primaria, desarrollado, en su mayor parte, mediante el uso de plataformas 2.0 y entornos digitales como herramienta de aprendizaje. Nuestro objetivo docente es alcanzar un óptimo desarrollo de las competencias descritas con una docencia adaptada a las nuevas tecnologías. Y nuestros objetivos de investigación se centran en diagnosticar qué papel posee el patrimonio en las etapas educativas del desarrollo integral de nuestros alumnos y qué concepción tienen de él, y conocer qué aspectos se modifican en esa noción de patrimonio tras la implementación del citado bloque temático. Inicialmente, se realiza un estudio exploratoriodiagnóstico mediante un cuestionario que indaga sobre la presencia de la educación patrimonial en sus etapas formativas y el concepto de patrimonio adquirido a lo largo de las mismas. De esta primera fase se obtienen datos cuantitativos de frecuencias y estadísticas, además de una primera definición de patrimonio. Posteriormente, se implementa el bloque correspondiente a la educación patrimonial y tras su desarrollo se vuelve a realizar la pregunta clave del cuestionario para analizar y comparar las definiciones del alumnado sobre el concepto de patrimonio. Esta segunda fase se desarrolla mediante una metodología pretest-postest, a través de un análisis de contenido con método mixto.

\section{Competencias docentes en Educación Patrimonial}

Hablar de competencias docentes en educación patrimonial significa trazar líneas de ruta en la formación inicial de los maestros, para que sean capaces de trabajar el patrimonio de forma global y transversal en cualquier materia, dada la riqueza de la disciplina y sus categorías. En este sentido, no se han encontrado estudios previos que nos indiquen las competencias a desarrollar en su formación inicial, aunque sí existen estudios como el de Castro y López-Facal (2019), que definen las necesidades existentes en la formación del profesorado, las ya adquiridas en maestros de educación primaria (Domínguez \& López-Facal (2017a) o la evaluación de las mismas (Sánchez-Macías \& Jorrín, 2017). También encontramos estudios que trabajan desde competencias clave de forma individual como es el caso de la social y cívica (Castro \& LópezFacal, 2018; Domínguez \& López-Facal, 2017b) o la digital (Ibáñez-Etxeberría et al., 2019; Solé, 2020; Tammaro, 2017).

Para que los futuros docentes sean capaces de trabajar adecuadamente el patrimonio en su práctica profesional, parece pertinente definir unas competencias mínimas propias de la educación patrimonial. Por ello, partiendo de la secuencia que establece Fontal (2003), se dispone un procedimiento simultáneo que muestra cómo los 7 procedimientos se integran dentro de nuestra formación en el grado de educación 
primaria y cómo el último de ellos, transmitir, se convierte en el pilar fundamental de las competencias docentes (Ayala, 2008). Para su definición se ha trabajado desde los instrumentos validados para la evaluación de programas de educación patrimonial (Calaf et al., 2017; Fontal et al., 2019), la teoría de la educomunicación del patrimonio descrita por Martín y Cuenca (2015), los vínculos establecidos por Fontal y Marín (2018) y las líneas presentes en el Plan Nacional de Educación Patrimonial (Domingo et al., 2013). Así mismo, se han revisado artículos previos que recogen las conceptualizaciones sobre el patrimonio de alumnos y profesores, tales como Jiménez et al. (2010) y Martín-Cáceres y Cuenca-López (2011); y los valores esperables en la formación docente y su desarrollo competencial en materia de patrimonio (Estepa et al., 2008).

Tabla 1

Relación de procedimientos y competencias docentes

$\begin{array}{cc}\begin{array}{c}\text { Procedimientos docentes } \\ \text { A partir de la secuencia procedimental (Fontal, } \\ 2003)\end{array} & \begin{array}{c}\text { Competencias docentes } \\ \text { A partir de Ayala (2008), Pérez (2005) y Tejada } \\ (2009)\end{array} \\ \text { Conocer } & \text { Competencia teórica }\end{array}$

- Se da a conocer el patrimonio en profundidad, sus categorías, su legislación, los órganos competentes, su evolución epistemológica y su presencia curricular.

- Se fomenta un conocimiento integral de todas las categorías, desde los factores de propiedad, pertenencia e identidad, a través del diálogo, la experimentación y los procesos de apropiación.

- Se trabaja la presencia del patrimonio en las materias de forma transversal.

- Se establecen conexiones entre el patrimonio y: a) el entorno próximo; b) otros ámbitos territoriales.

- Se trabajan, comparten y analizan proyectos existentes, artículos y líneas de investigación, para que conozcan diferentes enfoques y modos de trabajo y planificación en educación patrimonial.

\section{Comprender}

- Se favorece la comprensión del patrimonio como elemento en constante crecimiento y transformación mediante el análisis, los procesos reflexivos, la problematización y la indagación.

- A través de un trabajo experiencial, se trabaja su comprensión como "sedimento" de la cultura, que conforma las sociedades pretéritas y las actuales y que se continúa construyendo con vistas al futuro.

- Se trabaja no solo desde el patrimonio global, sino también desde lo local y particular, los significados, las experiencias de lo cotidiano y también de lo excepcional, relacionándolo con los intereses de los propios alumnos.

- Se proporcionan recursos y se seleccionan contenidos relacionados con su historia y con los contenidos curriculares en las diversas áreas de conocimiento.

\section{Didáctica}

- Demuestra uso y manejo de la legislación vigente en materia de patrimonio, curricular y organizativa, así como de variadas fuentes y recursos bibliográficos.

- Domina la disciplina y posee un concepto amplio del patrimonio holístico e integral desde una perspectiva simbólico-identitaria que trasciende los valores históricos, estéticos o económicos.

- Conoce los diferentes métodos de enseñanza del patrimonio y los pone en práctica en la planificación teórica de programas educativos definiendo las bases, criterios sobre los que se establece el programa.

- Diseña procesos y experiencias de aprendizaje significativos, experienciales, vinculantes, relacionales, simbólico-identitarios, reflexivos, creativos, indagadores, críticos y de debate, poniendo en práctica los trabajos vistos en su formación, empleando diferentes metodologías, estrategias, estilos, recursos y materiales, etc.

- Planifica de forma clara, precisa, ordenada y conectada las estructuras didácticas completas integrando en sus procesos el desarrollo de valores, competencias, conceptos, habilidades y actitudes.

- Facilita y guía los procesos de aprendizaje buscando el desarrollo integral del alumnado, proporcionando las claves y recursos necesarios para su conocimiento e interpretación.

- Se adecúa al nivel educativo de las etapas de formación, así como a sus intereses, inquietudes, 
- Se promueve la comprensión a través de la relación dialógica y la significación con los valores humanos.

- Se plantean propuestas que desafíen al estudiante en su medio de trabajo o en su resolución: supuestos, creación de píldoras de difusión del patrimonio, diseño de nuevas formas y espacios para ponerlo en valor o darlo a conocer, etc.

$$
\text { Respetar, valorar y cuidar }
$$

- Se fomentan actitudes de respeto, valoración y cuidado hacia las manifestaciones patrimoniales de diversa índole y origen.

- Se trabaja de forma múltiple y flexible desde la significación, la concienciación y el conocimiento de las diferentes manifestaciones fruto de las culturas y de la diversidad social.

- Se promueve una conciencia de responsabilidad social y compromiso patrimonial a través de los usos y valores del patrimonio, fomentando procesos reflexivos, identitarios, vivenciales, relacionales, vinculantes, experienciales y críticos.

- Se trabaja la puesta en valor del patrimonio desde un paradigma constructivo y problematizador, que permite debatir e intercambiar juicios críticos y de valor, normalmente trabajados desde patrimonios en conflicto de su entorno más próximo.

- Se da lugar a la libre interpretación y significancia, así como a la creación e intervención de nuevos -o ya existentes- patrimonios propios, partiendo de los intereses de los estudiantes y de sus contextos más cercanos.

\section{Disfrutar}

- Se trabaja desde un enfoque humanizado en el que el discente es creador, conocedor, mediador, destinatario, agente de valoración y transmisor del patrimonio.

- Se fomenta el descubrimiento, la creación de nuevos patrimonios, comunidades, redes patrimoniales a través de propuestas educativas, la intervención en nuestros patrimonios o su difusión. - Se establecen diálogos con los patrimonios propios y ajenos a través del proceso relacional permitiendo situar al discente en el centro del aprendizaje.

- Se fomentan procesos de indagación e investigación con los bienes patrimoniales y su contexto.

- Se trabajan las narrativas históricas y se profundiza en el valor de los bienes y de las tradiciones. Se trabaja sobre sus significados y se exploran las formas de relación con nuestro legado. diversidad de aprendizajes, contextos y diferentes materias.

- Relaciona los contenidos con la realidad más próxima del estudiante.

- Emplea las Tecnologías de la Información y la Comunicación con el objetivo de aproximar, motivar, dinamizar, complementar o indagar sobre el patrimonio.

\section{Social}

- Planifica teniendo presente el componente social asociado al patrimonio, la identidad, los significados y la memoria, favoreciendo el proceso de apropiación simbólica.

- Plantea actividades para el conocimiento de las diferentes culturas, contextos y manifestaciones fomentando actitudes de valor, respeto y cuidado de los diversos patrimonios.

- Coopera y colabora en redes de trabajo, y participa o desarrolla proyectos interdisciplinares, interterritoriales, interculturales, etc.

- Visibiliza y da a conocer sus prácticas como eje de colaboración e intercambio social para continuar mejorando en la disciplina.

- Trabaja en equipo con profesionales de su institución o de instituciones externas y con otras instituciones proponiendo nuevos proyectos que contribuyan al aprendizaje experiencial del alumno y la aproximación al patrimonio.

- Demuestra y aplica un enfoque social del patrimonio demostrando actitudes de compromiso, valor, respeto y cuidado hacia el mismo.

\section{Innovación}

- Busca implementar nuevas dinámicas, metodologías y estrategias innovadoras en su planificación educativa para trabajar el patrimonio y fomentar nuevas experiencias de aprendizaje e indagación en el alumnado.

- Busca ser un docente consciente y activo en el constante proceso de cambio en educación y en un contexto intercultural.

- Se muestra abierto a la participación activa en procesos de investigación e innovación educativa y disciplinar.

- Promueve y participa en el trabajo en equipo.

- Participa y fomenta proyectos de investigación e innovación educativa.

- Se recicla y forma de manera continuada, actualizando sus conocimientos y fortaleciendo sus puntos débiles.

- Promueve el intercambio de proyectos, experiencias, alumnos, profesores y el conocimiento de otros contextos. 
- Se busca la experiencia desde el contacto directo, sentirlo a través de la didáctica de los objetos, sus fuentes y lugares in situ (museos, yacimientos, paisajes, lugares históricos, etc.). Se apela a los sentidos y a las emociones a través de los procesos vinculantes.

\section{Transmitir}

- Se da paso a la enseñanza, a la comunicación y a la difusión del patrimonio en su más amplio e integral abanico de posibilidades a través de los diferentes medios, en su mayoría tecnológicos, para obtener mayor visibilidad y alcance social.

- Se fomentan procesos creativos de transmisión o documentación del patrimonio apelando a las narrativas emocionales y sensoriales que estimulen al receptor o lo haga partícipe y activo de la historia y del proceso de sensibilización y aprendizaje.

- Se trabaja la educomunicación del patrimonio a través de la organización de ideas, la combinación de imágenes, sonidos y textos, la creación de microvideos, la realización e intervención de fotografías, el empleo del storytelling, la gamificación del patrimonio, campañas publicitarias, de concienciación, sensibilización; creación de espacios virtuales como blogs o webs para compartir patrimonios, fomentar diálogos $\mathrm{y}$ debates $\mathrm{O}$ simplemente para contenerlos y darlos a conocer.

- Se trabaja la transmisión del patrimonio como base del aprendizaje informal mediante el aprovechamiento de las infraestructuras y medios digitales actuales, el uso de apps o redes sociales para dinamizar y multimediar el patrimonio.

\section{Sensibilizar}

- Fin último de la secuencia procedimental que busca sensibilizar al alumnado con el patrimonio y lograr que mediante su trabajo y creaciones busquen la sensibilización de los otros.

- Se trabaja a través de todos los procedimientos anteriores brindando al alumnado nuevos conceptos, miradas y significados del patrimonio. Facilitando nuevos modelos de enseñanza, recursos y políticas patrimoniales.

- Se comparten prácticas singulares que reflejan un trabajo basado en los valores, en los conocimientos e historias que los patrimonios nos aportan; basados en la identidad, en la autenticidad, fragilidad y el respeto por nuestra herencia. Solo así se consigue una sensibilización global que permita la reverberación del aprendizaje, que sea significativo y, por tanto, aplicable en su práctica futura, comprendiendo un enfoque global e implementado de forma transversal.
- Diseña materiales, recursos e instrumentos propios e innovadores para ampliar o favorecer los procesos de enseñanza-aprendizaje del patrimonio.

Comunicativa

- Adecúa tanto su lenguaje -siendo este preciso y comprensible-, como los recursos textuales y fuentes utilizadas en el aula atendiendo a su diversidad, para favorecer la comprensión de las categorías patrimoniales y la interpretación de las múltiples contribuciones culturales, sociales, artísticas, económicas, etc.

- Estimula la comunicación multidireccional, el diálogo, el debate, las argumentaciones, etc., en las propuestas educativas implementadas en el aula.

- Sabe ser y sabe estar. Es capaz de relacionarse e interactuar de manera cooperativa/colaborativa con otras personas en su contexto profesional.

- Basa su comunicación en un espíritu socio-crítico, abierto y dialogante para formar ciudadanos comprometidos con el desarrollo sostenible en el ámbito patrimonial.

- Integra en su discurso un enfoque holístico del patrimonio, desde una perspectiva significativa e integral de la cultura e introduciendo factores socioemocionales.

- Fomenta la valoración de los patrimonios internos y externos a la propia cultura y el compromiso con su cuidado, valoración y respeto.

\section{Evaluativa}

- Evalúa el proceso de aprendizaje del alumno y es responsable de la mejora continua de su grupo, retroalimentando su desarrollo.

- Diseña herramientas y sistemas de evaluación, tablas de valores, rúbricas, escalas, matrices de observación, en cualquier contexto de trabajo.

- Tiene en cuenta la evolución cuantitativa y cualitativa del alumnado de forma individual $y$ colectiva.

- Integra diferentes sistemas de evaluación (heteroevaluación, coevaluación, autoevaluación).

- Muestra capacidad autocrítica de su propia práctica y labor docente y formativa mediante la autoevaluación, análisis, revisión y mejora.

- Contribuye activamente en la mejora de la calidad educativa. 


\section{Plataformas digitales como herramienta de enseñanza-aprendizaje desde nuestra práctica docente en educación patrimonial}

Teniendo presentes los procedimientos que deben trabajarse en el aula para alcanzar el desarrollo de competencias docentes que han de implementar en su futuro próximo, nuestro modelo de educación patrimonial se estructura en base a tres pilares fundamentales: (a) la realización de actividades teóricoprácticas con un alto grado de creatividad y experimentación [competencias teórica, didáctica y comunicativa]; (b) propuestas diseñadas bajo la premisa del fomento de la reflexión, la resolución, el pensamiento crítico y la indagación en entornos que requieran el empleo de las TIC y plataformas 2.0 que fomenten el intercambio y la coconstrucción del conocimiento [competencias social y de innovación]; y (c) actividades que potencian la aplicación, reformulación y el diseño y evaluación de nuevas propuestas educativas [competencias didáctica y evaluativa]. Por último, se recurre a la exposición grupal de los proyectos, lo que promueve procesos de comunicación entre el alumnado y fomenta actitudes empáticas y de respeto. A partir de este modelo educativo, el alumnado no solo resuelve y crea, sino que planifica y reformula propuestas en materia de patrimonio, integrando los conocimientos adquiridos. Los alumnos experimentan el patrimonio a través de apps o visitas virtuales a espacios patrimoniales, exploran webs, proyectos y recursos en red y trabajan desde la fotografía, las videocápsulas o los microrrelatos a través de aplicaciones que brindan un espacio de debate e intercambio de creaciones. Además, se fomenta la participación en propuestas en red, y el diseño y creación de wikis, webs, blogs o espacios 2.0 desde un enfoque personal o colectivo que permita la participación y construcción social y colaborativa. Igualmente, se estimula la creación de comunidades virtuales a través de los hashtag y redes sociales, tales como Facebook, Twitter o Instagram.

\section{Método}

La presente investigación se realiza a partir de un enfoque mixto, en cuya primera fase tiene un carácter exploratorio, se tratan los datos de manera cuantitativa mediante un cuestionario que nos permite extraer frecuencias en las respuestas, a modo de evaluación diagnóstica; mientras que en la segunda fase se enfatiza en los aspectos descriptivos a través de un análisis de contenido sistemático (Piñuel, 2002) mediante la metodología comparada pretest-postest, que analiza la definición de patrimonio que el alumnado construye antes y después de la implementación educativa referente a la educación patrimonial, efectuada sobre los pilares metodológicos anteriormente descritos. El pretest responde a los conocimientos adquiridos en las etapas formativas anteriores al grado universitario, mientras que el postest se corresponde con los adquiridos en su formación universitaria actual, y es a través de este segundo análisis cuando comprobamos el grado de desarrollo de las competencias docentes (véase teórica y comunicativa).

Este estudio forma parte de una investigación más amplia cuyo objetivo general es evaluar las competencias docentes desarrolladas a lo largo de su formación, a partir de unas rúbricas derivadas de las concreciones del desempeño docente descritas en las 6 competencias de la tabla 1. Sin embargo, este estudio se centra en el OE1: conocer qué conocimientos previos sobre patrimonio han adquirido los alumnos durante su formación y el OE2: comparar en qué grado nuestro método educativo modifica su concepto. Para ello, se ha aplicado un cuestionario de 6 preguntas para conocer si su concepción de patrimonio se transforma tras la aplicación del método secuencial y si esa reconceptualización integra términos que nos permitan identificar un concepto integral del patrimonio, un compromiso y una sensibilización hacia el mismo. El estudio se amplía con la observación del aula, la práctica y participación de los alumnos, combinando el método principal con las bases establecidas por Simons (2011) para el estudio de casos.

\subsection{Participantes}

El desarrollo del estudio se inició con una muestra de 143 alumnos, que finalmente se ha constituido por N=132 alumnos de segundo curso de "Grado de Maestro en Educación Primaria" que realizaron los pretest/postest a lo largo de los cursos académicos 2017/2019. En base a los test, se estudia y analiza el contenido de sus respuestas, con el objetivo de identificar los conceptos clave que han adquirido centrándonos en las competencias teórica, social y comunicativa. 


\subsection{Instrumentos}

Los instrumentos de recogida de datos se basan en un cuestionario aplicado antes y después de la implementación de los contenidos. El primer cuestionario está compuesto por un mayor número de ítems tipo test ya que tiene el objetivo de obtener datos descriptivos sobre el papel y la presencia del patrimonio en su formación previa; de este proceso se analizan las frecuencias de respuesta de forma cuantitativa, además de recoger la definición inicial de patrimonio que será analizada cualitativamente. El segundo cuestionario solo plantea dos preguntas clave sobre las categorías y el concepto del patrimonio que se deben responder de manera narrativa tras la intervención educativa. Esta fase comparativa conforma el grueso del estudio, mediante el análisis cualitativo de los datos con el programa Nudist Vivo (v. 12), que nos permite la codificación sistemática de los datos y el establecimiento de categorías, bajo un análisis estadísticodescriptivo de tipo semántico-relacional (Fontal \& Marín, 2018).

\section{Resultados}

\subsection{Estudio exploratorio, cuestionario diagnóstico}

Para conocer qué papel ha desempeñado la educación patrimonial en la formación previa a la etapa universitaria en los participantes del estudio, se pide a los discentes que cumplimenten un cuestionario cuyo primer objetivo es (a) saber en qué grado el patrimonio ha estado presente durante su formación y en qué etapas educativas. En base a ello, los resultados arrojan que la presencia del patrimonio en su formación es insuficiente ya que un $80 \%$ de la muestra nos indica que el patrimonio ha estado presente de forma muy superficial [ $2 \%$ nada; $31 \%$ poco; $47 \%$ algo], frente a un $20 \%$ que manifiesta haber tenido una formación más completa y adecuada [15\% bastante; $5 \%$ mucho]. Respecto a las etapas educativas donde el patrimonio ha tenido una mayor presencia, un $80 \%$ señalan las más próximas a su realidad educativa [ $51 \%$ ESO; $27 \%$ bachillerato; $2 \% \mathrm{FP}$, un $11 \%$ señala la etapa primaria y solo un $9 \%$ manifiesta que el grado universitario es la etapa con mayor presencia de esta disciplina, lo que nos enfrenta a un importante reto dado que no se está trabajando en otras materias.

\section{Figura 1}

Gráfico de respuestas sobre la pregunta: En qué intervalos formativos crees que ha estado más presente el concepto de patrimonio

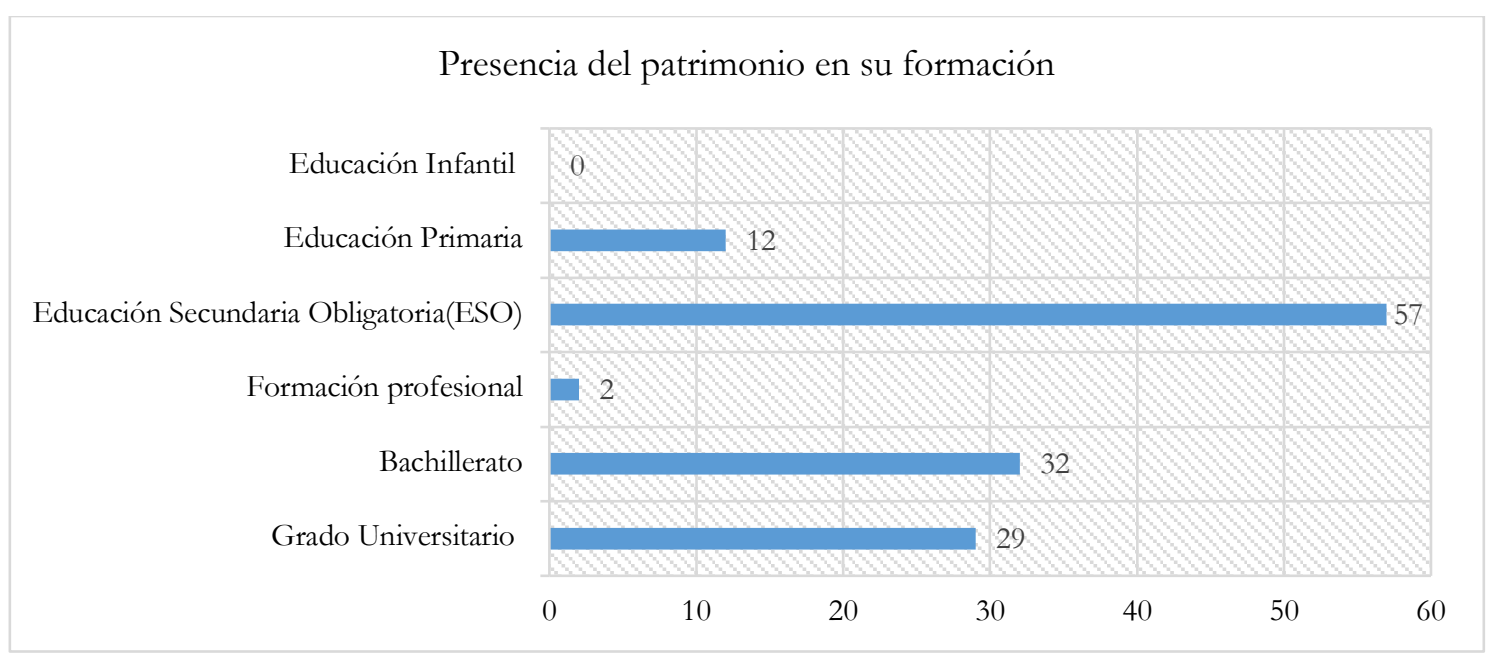

El segundo objetivo es (b) conocer si han participado en algún proyecto o actividad específica de patrimonio en el ámbito formal y no formal. En este caso, subrayamos que un $50 \%$ de los alumnos no han participado de ninguna actividad o proyecto $(14,4 \%)$ o no lo recuerdan $(36,3 \%)$, lo que supone que, aunque si hayan tenido la experiencia, no ha sido significativa para ellos. 


\section{Figura 2}

Gráfico de respuestas sobre la pregunta: ¿Recuerdas haber participado en alguna actividad o proyecto de patrimonio?

Participación en actividades y proyectos de patrimonio

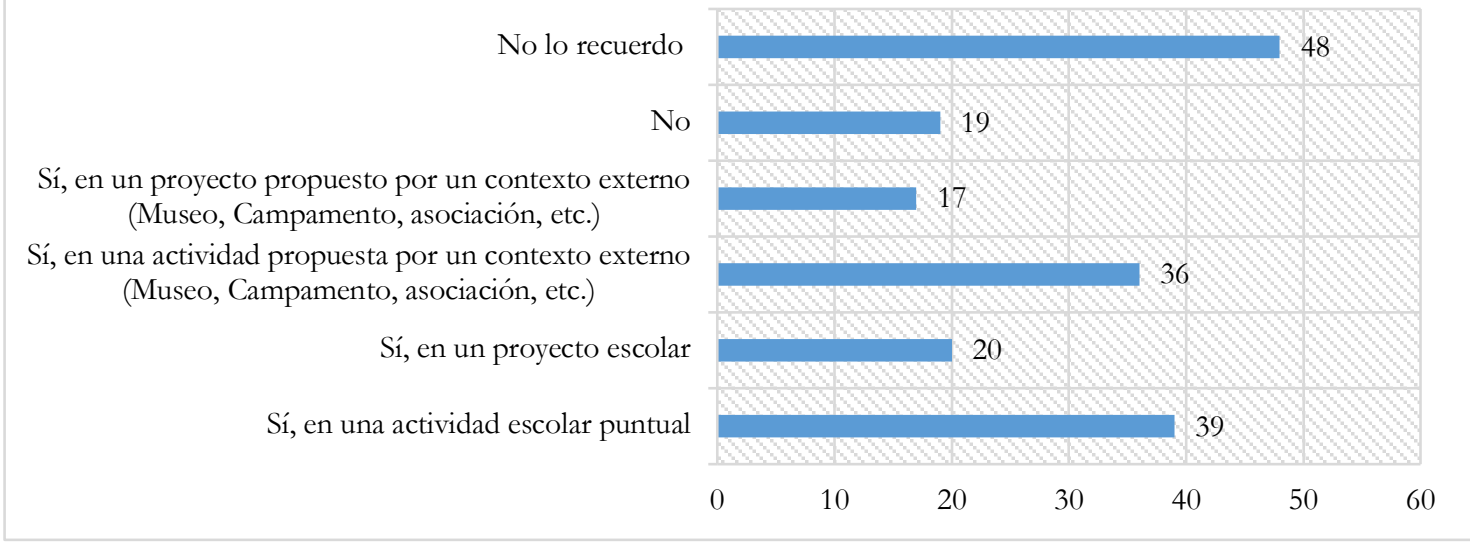

Sin embargo, la última de las cuestiones formuladas para (c) conocer el grado de sensibilización que tienen hacia el patrimonio, pone de manifiesto que un $73 \%$ otorga al patrimonio un valor elevado [32\% mucho; $41 \%$ bastante], por lo que esta predisposición facilita la sensibilización con el mismo a partir de la perspectiva simbólico-identitaria, de compromiso y valoración. Solo un $23 \%$ le da algo de valor y un $4 \%$ poco. Como podemos observar en la figura 3, se han comparado los datos del valor que otorgan a la presencia del patrimonio en su formación y el valor que ellos le dan de forma personal, y el último factor presenta valores más altos, lo que indica una sensibilización adquirida bien por aprendizaje informal o bien por un trabajo indirecto o transversal que no ha sido identificado. En cualquier se manifiesta necesaria una mayor presencia en las aulas.

\section{Figura 3}

Gráfico comparativo de respuestas sobre las preguntas: ¿En qué grado el patrimonio ha estado presente durante su formación? y ¿Qué valor le das tú al patrimonio?

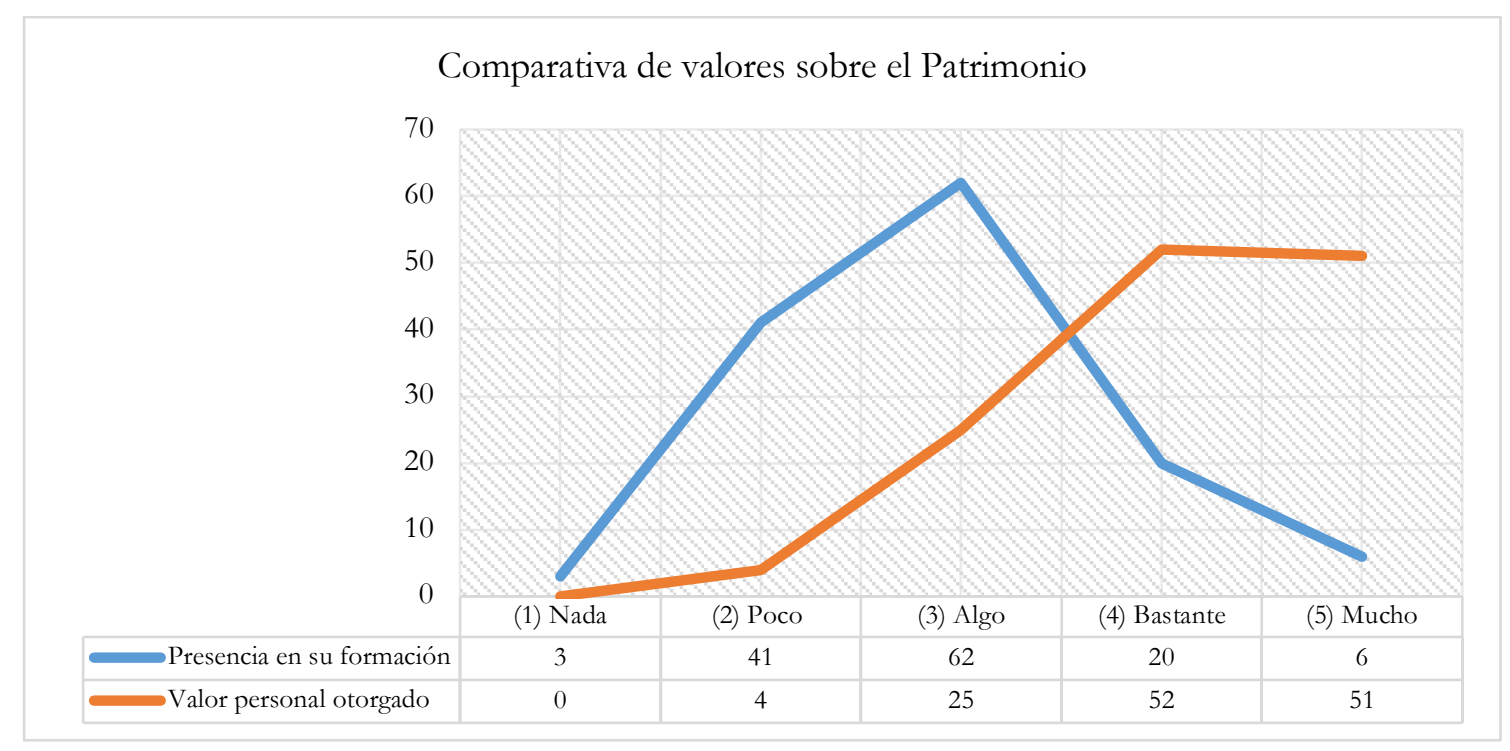

\subsection{Estudio comparativo, pretest-postest}

Tras las cuestiones exploratorias descritas, se plantean dos preguntas clave ¿qué tipos o categorías de patrimonio conoces? y ¿qué es patrimonio para ti?, principales elementos comparativos de análisis para conocer si se produce una reconceptualización y ampliación del concepto tras la implementación del bloque de educación patrimonial. Estos interrogantes se plantean al inicio y al final de las asignaturas codificando las respuestas y comparando los términos y sus frecuencias. 
En primer lugar, atendiendo a las categorías de patrimonio que los alumnos identifican en sus respuestas, se muestran los términos obtenidos en el pretest y el postest, así como un gráfico de columnas que nos permite comparar visualmente los valores.

Tabla 2

Comparación de frecuencias obtenidas en el pretest-postest sobre las categorías de patrimonio

\begin{tabular}{|c|c|c|c|}
\hline Categorías de patrimonio & Pretest & Categorías de patrimonio & Postest \\
\hline Cultural & 67 & Cultural & 103 \\
\hline Histórico & 17 & Histórico & 39 \\
\hline $\begin{array}{l}\text { Artístico: escultura (4), pintura (20), } \\
\text { cine (1), teatro (1) y monumentos (1) }\end{array}$ & 65 & Artístico: escultura (3) y pintura (5) & 112 \\
\hline Arqueológico & 2 & Arqueológico & 24 \\
\hline Arquitectónico & 9 & Arquitectónico & 14 \\
\hline Musical & 8 & Musical & 15 \\
\hline Documental & 7 & Documental & 20 \\
\hline Natural: ambiental (2) & 31 & $\begin{array}{l}\text { Natural: biológico (1), geológico (1), } \\
\text { geográfico (2) y paisajístico (15) }\end{array}$ & 78 \\
\hline Material/tangible & 13 & Material/tangible & 54 \\
\hline Literario & 2 & Literario & 14 \\
\hline Religioso & 3 & Religioso o eclesiástico & 15 \\
\hline Industrial & 9 & Industrial & 39 \\
\hline Económico & 8 & Económico & 2 \\
\hline Etnológico/etnográfico & 3 & Etnológico/etnográfico & 17 \\
\hline $\begin{array}{l}\text { Inmaterial/intangible: gastronómico } \\
\text { (1) }\end{array}$ & 13 & $\begin{array}{l}\text { Inmaterial: gastronómico y culinario } \\
\text { (4), tradiciones (16), festividades (10), } \\
\text { lingǘstico (14), Costumbres (5), } \\
\text { haceres (1), creencias (1), popular (1), } \\
\text { ético (1) y mental, ideas e intelectual } \\
\text { (5) }\end{array}$ & 122 \\
\hline $\begin{array}{l}\text { Patrimonios aislados: empresarial (1) } \\
\text { sanitario (1), científico (2) y nobiliario (1) }\end{array}$ & ). 4 & $\begin{array}{l}\text { Patrimonios aislados: vestimentas (1), } \\
\text { político (1), militar (1) y rural (1). }\end{array}$ & 4 \\
\hline
\end{tabular}

Figura 4

Gráfico comparativo de respuestas sobre las categorías de patrimonio

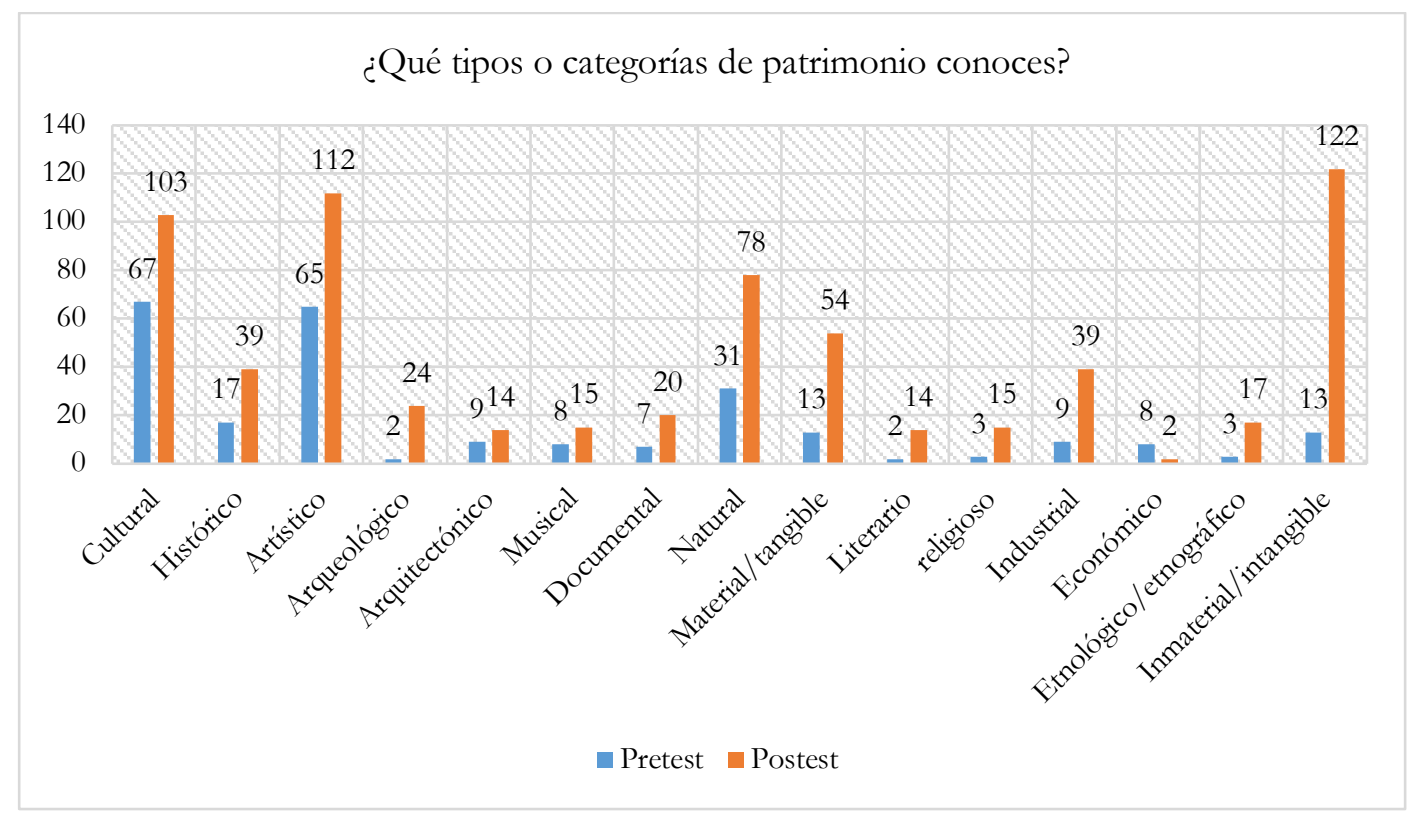


A través de sus respuestas podemos observar, por un lado, cómo se incrementan y enriquecen las categorías de patrimonio a las que aluden, ampliando los términos y explicando sus contenidos y, por otro, más importante si cabe, cómo se transforma su percepción dando una mayor importancia al patrimonio inmaterial que previamente se mencionó de forma tímida. A través de la experimentación y el trabajo de aula se detonan una serie de valores que les vinculan a elementos inmateriales por encima de los materiales, despertando afectos, valores y vínculos que amplían y modifican su concepción original. De igual modo, se mantienen algunas categorías como el cultural y artístico; se observa un aumento general de los valores, y se subraya la única disminución existente que responde a una concepción escasa del patrimonio, el económico.

En base a la pregunta ¿qué es patrimonio para ti? , en las respuestas iniciales se observa un sentido de propiedad o pertenencia del patrimonio que posteriormente es trabajado en el aula de forma amplia. Para ello nos basamos en un trabajo reflexivo e indagador sobre los organismos competentes internacionales y nacionales en materia de patrimonio, y en los diferentes niveles de propiedad, trabajando desde lo particular a lo global a través de la web www.personasypatrimonios.com. A través de este espacio digital se crean puntos de encuentro entre los patrimonios, se dialoga y se construyen nuevos significados.

\section{Figura 5}

Gráfico comparativo de respuestas sobre la propiedad patrimonial

Gráfico comparativo sentido de propiedad

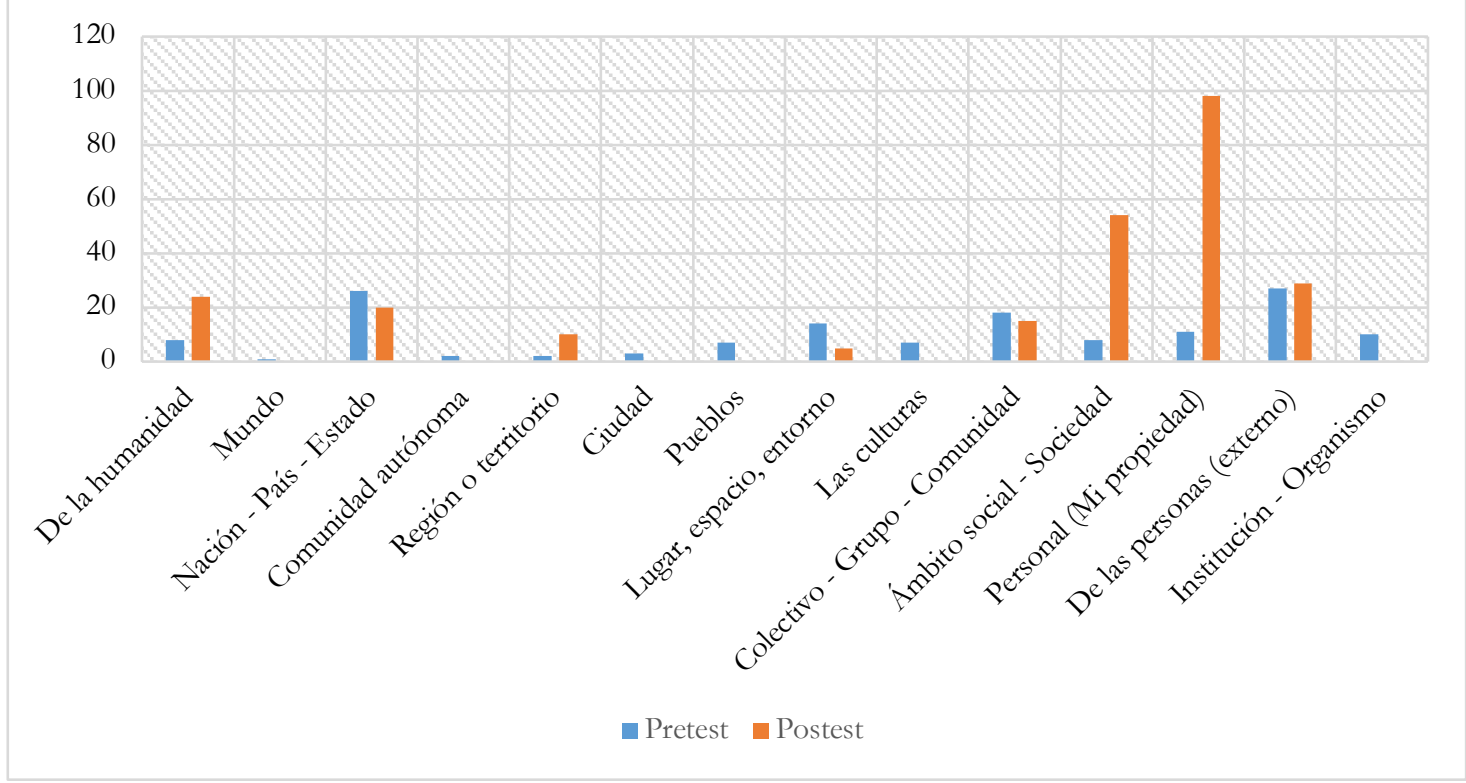

En la figura 5 podemos comprobar cómo a través de esta profundización e intercambio se modifica su sentimiento de propiedad y pertenencia, de una perspectiva totalmente alejada de un patrimonio propio, dependiente del estado, de instituciones, personas, lugares o colectivos, a una propiedad social, que nace de y para las personas.

Finalmente, se ha trabajado en profundidad el análisis sobre las respuestas del postest ya que las definiciones son mucho más amplias y enriquecedoras que las iniciales, lo que demuestra que se amplía y transforma el concepto patrimonial. Su definición conecta con el nivel máximo de desarrollo, una perspectiva simbólica, identitaria y humanista. Son capaces de identificar los usos, valores y efectos que el patrimonio aporta de forma personal y como miembro de una sociedad y, en tercer lugar, son capaces de integrar la responsabilidad y el compromiso adquirido: conservación, protección, valoración, cuidado o preservación son los más manifestados. 
Tabla 3

Codificación de las respuestas sobre la pregunta: ¿Qué es patrimonio para ti?

\begin{tabular}{|c|c|c|c|c|c|c|}
\hline $\begin{array}{l}\text { Definen patrimonio } \\
\text { como: }\end{array}$ & Pre & Post & $\begin{array}{l}\text { Aquello que... } \\
\text { (Usos, valores, } \\
\text { aportes) }\end{array}$ & Post & Responsabilidad & Post \\
\hline $\begin{array}{l}\text { Bienes / conjunto de } \\
\text { bienes }\end{array}$ & 92 & 34 & $\begin{array}{l}\text { Conforma nuestro } \\
\text { bagaje cultural y } \\
\text { educativo de forma } \\
\text { significativa }\end{array}$ & 2 & Transmitir & 5 \\
\hline $\begin{array}{l}\text { Propiedades o } \\
\text { posesiones }\end{array}$ & 30 & 19 & $\begin{array}{l}\text { Construye } \\
\text { historia, valores y } \\
\text { sociedad }\end{array}$ & 3 & Conservar & 18 \\
\hline $\begin{array}{l}\text { Indefinido (aquello que, } \\
\text { algo que, cosas, } \\
\text { conjunto de cosas, } \\
\text { elementos, conjunto de } \\
\text { elementos) }\end{array}$ & 28 & 24 & $\begin{array}{l}\text { Representa algún } \\
\text { aspecto de nuestra } \\
\text { condición de seres } \\
\text { humanos; culturas, } \\
\text { zonas o pensamientos. }\end{array}$ & 19 & Legar & 1 \\
\hline Derechos & 3 & 1 & Nos identifica & 15 & Compromiso & 2 \\
\hline Obligaciones & & 1 & Nos caracteriza & 20 & Cuidar & 9 \\
\hline Legado & & 2 & Nos define & 29 & Proteger & 10 \\
\hline Vestigio & & 3 & $\begin{array}{l}\text { Se asocia a las vivencias, } \\
\text { el apego o los valores }\end{array}$ & 5 & Respetar & 7 \\
\hline $\begin{array}{l}\text { Todo lo que tiene } \\
\text { importancia social o } \\
\text { histórica }\end{array}$ & & 5 & $\begin{array}{l}\text { Nos permite conocer } \\
\text { hechos, sociedades y } \\
\text { formas de vida }\end{array}$ & 7 & Salvaguardar & 6 \\
\hline Relaciones & & 39 & Heredamos & 28 & Apreciar & 3 \\
\hline Vínculos & & 68 & Dotamos de valor & 9 & Estudiar & 4 \\
\hline Conexiones & & 14 & & & $\begin{array}{l}\text { Gestionar } \\
\text { Mantener } \\
\text { Realzar } \\
\text { Mostrar } \\
\text { Valorar } \\
\text { Educar } \\
\text { Preservar }\end{array}$ & $\begin{array}{c}1 \\
1 \\
1 \\
1 \\
11 \\
3 \\
12\end{array}$ \\
\hline
\end{tabular}

\section{Conclusiones y discusión}

Desde la trayectoria evaluativa desarrollada en materia de educación patrimonial, los diversos estudios de caso, los grupos de discusión y la propia evaluación de los diseños educativos (Castro \& López-Facal, 2019; García-Ceballos et al., 2017; Rivero et al., 2018), han ido manifestando la ausencia de una formación adecuada y continua de los profesionales del patrimonio y, por ende, de las nuevas generaciones (Conde \& Armas, 2019). A través de la consecución de los objetivos propuestos en el estudio, esta conclusión se ha visto nuevamente constatada, ya que tan solo un $20 \%$ de los participantes indicó haber tenido una formación adecuada, lo que resulta un dato preocupante para afrontar las nuevas demandas, desafíos y retos del siglo XXI (Klarin, 2016; Pérez, 2005; Solé, 2020). La primera fase del estudio nos permite concluir la necesidad de reflexionar y rediseñar la praxis docente para salvar la importante brecha existente entre la educación recibida por los futuros docentes en su etapa de educación obligatoria y la que deben recibir en la actualidad, dado que no existe una correlación entre los conocimientos que deben transferir y los que actualmente poseen (Fontal \& García-Ceballos, 2019). Diversos estudios han analizado la presencia del patrimonio en el currículo educativo en sus diferentes etapas mostrando resultados muy dispares entre unas y otras comunidades y materias (Martínez-Rodríguez \& Fontal, 2020; Pinto \& Molina, 2015), sin embargo, aunque el patrimonio si está presente en la teoría, no se refleja en la práctica y las carencias siguen siendo acusadas, se ha dado un paso necesario pero insuficiente hacia la implementación (Pepper, 2011). La ausencia de una formación adecuada en patrimonio, o su escasa presencia, subraya la adquisición de concepciones reduccionistas ya señaladas en investigaciones anteriores como Estepa et al. (2008) o Jiménez et al. (2010), que además de esta reflexión, ya planteaban la reconsideración de la materia desde la formación inicial. Lamentablemente, una década después los análisis continúan apuntando hacia los mismos resultados. 
La segunda parte del estudio que planteaba analizar la transformación conceptual que se produce antes y después de impartir el bloque temático de educación patrimonial, detecta notables cambios tras la intervención. Entre ellos destacan la multiplicación de enfoques sobre el concepto patrimonio, los valores y compromisos adquiridos y la significativa transformación del sentimiento de pertenencia, de un patrimonio del Estado a un patrimonio personal y social, aspectos fundamentales recogidos en la secuencia procedimental (Fontal, 2003). Estos resultados encuentran convergencias con otros estudios que han implementado intervenciones didácticas, cuyo pilar fundamental era la transmisión del patrimonio, que han alcanzado cambios significativos como la comprensión de una dimensión integral e identitaria de la memoria y el legado cultural (Castro \& López-Facal, 2018) o la concienciación y fomento de la conservación (Molina, 2017).

Son diversos los interrogantes que se plantean algunos autores sobre las competencias requeridas para los profesionales del patrimonio, los roles emergentes y las competencias digitales (Carvalho \& Matos, 2018; Ibáñez-Etxeberria et al., 2019; Tammaro, 2017). Son muchos los planteamientos para continuar la línea de investigación, sin embargo, los puntos de encuentro existentes en este estudio (educación patrimonial, competencias docentes el empleo de plataformas digitales 2.0 y entornos digitales) nos han permitido gestar una manera innovadora y eficaz de enfocar la enseñanza-aprendizaje del patrimonio en la formación inicial de los futuros maestros de Primaria.

El reto a conseguir es extender dicha formación a los futuros profesores de etapas secundarias (ESO y Bachillerato), lo que permitirá dotar a todos los docentes de competencias, conocimientos, habilidades y actitudes relacionadas con la Educación Patrimonial, pudiendo convertir así a esta disciplina transversal en un referente en la educación del siglo XXI.

Apoyos

Ministerio de Economía y Competitividad de España (MINECO) y el Fondo Europeo de Desarrollo Regional (FEDER).

\section{Referencias}

Ayala, F. (2008). El modelo de formación por competencias, s/f.

Calaf, R., San Fabián, J.L. y Gutiérrez, S. (2017). Evaluación de programas educativos en museos: Una nueva perspectiva. Bordón, 69(1), 45-65. 10.13042/Bordon.2016.42686

Cano, E. (2005). Cómo mejorar las competencias docentes. Guia para la autoevaluación y el desarrollo de las competencias del profesorado. Graó.

Cañadas, L., Santos-Pastor, M. L. y Castejón, F. J. (2009). Competencias docentes en la formación inicial del profesorado de educación física. Retos: nuevas tendencias en educación física, deporte y recreación, 35, 284288.

Carvalho, A. \& Matos, A. (2018). Museum Professionals in a Digital World: Insights from a Case Study in Portugal. Museum International, 70(1-2), 34-47. 10.1111/muse.12191

Castro, B. y López-Facal, R. (2018). Patrimonio cultural y competencias sociales: bases para una propuesta de intervención didáctica en Portomarín. Educatio Siglo XXI, 36(1), 129-148. http://dx.doi.org/10.6018/j/324201

Castro, L. y López-Facal, R. (2019). Educación patrimonial: necesidades sentidas por el profesorado de infantil, primaria y secundaria. Revista Interuniversitaria de Formación del Profesorado, 94(33.1), 97-114.

Miguélez, J. C. y Castro, X. A. (2019). Representaciones sociales del alumnado de educación primaria sobre el patrimonio: estudio por medio de la asociación de palabras. Revista Interuniversitaria de Formación del Profesorado, 33(2), 187-201.

Chng, K.S. \& Narayanan, S. (2017). Culture And social identity in preserving cultural heritage: an experimental study. International Journal of Social Economics, 44(8), 1078-1091. https://doi.org/10.1108/IJSE---10---2015---0271

Conde, J., \& Armas, X. (2019). Social representations of primary education students on heritage. Study by the word association. Revista Interuniversitaria de Formación del Profesorado-Rifop, (94), 187-201. https://doi.org/10.9685/i3527

Consejo de Europa (2005). Council of Europe Framework Convention on the Value of Cultural Heritage for Society 27-X-2005. Council of Europe Treaty Series, 199. Recuperado de https://rm.coe.int/CoERMPublicCommonSearchServices/DisplayDCTMContent?documentId=09 $\underline{00001680083746}$ 
Consejo de Europa (2006). Recommendation of the European Parliament and of the Council of 18 December 2006 on key competences for lifelong learning. Official Journal of the European Union, (12), 10 18.

Domingo, M., Fontal, O., y Ballesteros, P. (Coords.) (2013). Plan Nacional de Educación y Patrimonio. Ministerio de Educación, Cultura y Deporte, Secretaría de Estado de Cultura.

Domínguez, A. y López-Facal, Ramón. (2017a). Formación de maestros y educación patrimonial. Estudios pedagógicos (Valdivia), 43(4), 49-68. https://dx.doi.org/10.4067/S0718-07052017000400003

Domínguez, A. y López-Facal, R. (2017b). Patrimonios en conflicto, competencias cívicas y formación profesional. Revista de Educación, 375, 86-109.

Estepa, J., Ávila, R.M. \& Ferreras, M. (2008). Primary and secondary teachers' conceptions about heritage and heritage education: A comparative analysis. Teaching and Teacher Education, 24(8), 2095-2107. 10.1016/j.tate.2008.02.017

Feldman, J. (2017). Memorylands: Heritage and Identity in Europe Today. American Ethnologist, 44(1), 145146.

Fontal, O. (2003). La educación patrimonial. Teoría y práctica en el aula, el museo e internet. Trea.

Fontal, O., y García-Ceballos, S. (2019). Las plataformas 2.0 como herramientas de aprendizaje y adquisición de competencias en educación patrimonial. RIFOP, 94(33.3), 285-306. https://doi.org/10.9685/73351

Fontal, O., García-Ceballos, S., Arias, B., y Arias, V. B. (2019). Evaluación de la calidad de programas de educación patrimonial: construcción y calibración de la escala Q-Edutage. Revista de Psicodidáctica, 24(1), 31-38. https:// doi.org/10.1016/j.psicod.2018.07.003

Fontal, O., Ibáñez, A., Martínez, M. y Rivero, P. (2017). El patrimonio como contenido en la etapa de Primaria: del currículum a la formación de maestros. Revista Electrónica Interuniversitaria de Formación del Profesorado, 20(2), 79-95. http://dx.doi.org/10.6018/reifop.20.1.286321

Fontal-Merillas, O., \& Marín-Cepeda, S. (2018). Nudos Patrimoniales. Análisis de los vínculos de las personas con el patrimonio personal. Arte, Individuo Y Sociedad, 30(3), 483-500. https://doi.org/10.5209/ARIS.57754

García-Ceballos, S., Amaral, L., \& Olivar, J.S. (2017). La Educación Patrimonial en el contexto no formal de São Paulo (Brasil): Plataforma Paranapiacaba: memoria y experimentación. Estudios pedagógicos, 43(4), 91-113. http://dx.doi.org/10.4067/S0718-07052017000400005

Ibáñez-Etxeberria, A., Kortabitarte, A., De Castro, P. y Gillate, I. (2019). Competencia digital mediante apps de temática patrimonial en el marco DigComp. Revista Electrónica Interuniversitaria de Formación del Profesorado, 22(1), 13-27. http://dx.doi.org/10.6018/reifop.22.1.356231

Jiménez, R., Cuenca-López, J.M. \& Ferreras, M. (2010). Heritage education: exploring the conceptions of teachers and administrators from the perspective of experimental and social science teaching. Teaching and Teacher Education, 26(6), 1319-1331. 10.1016/j.tate.2010.01.005

Martín-Cáceres, M.J. y Cuenca, J.M. (2011). La enseñanza y el aprendizaje del patrimonio en los museos: la perspectiva de los gestores. Revista de Psicodidáctica, 16(1), 99-122.

Martín-Cáceres, M.J. y Cuenca-López, J.M. (2015). Educomunicación del patrimonio. Educatio Siglo XXI, 33(1), 33-54. https://doi.org/10.6018/i/222491

Martínez Rodríguez, M., \& Fontal Merillas, O. (2020). Dealing with heritage as curricular content in Spain's primary education. Curriculum Journal, 31(1), 77-96. https://doi.org/10.1002/curj.7

Molina, M.P. (2017). La aplicación de Google Earth para la Educación Patrimonial en Ciencias Sociales. ReiDoCrea, 6, 221-228.

Pepper, D. (2011). Assessing key competences across the curriculum - and Europe. European Journal of Education, 46(3), 335-353. 10.1111/j.1465-3435.2011.01484.x

Pérez, J.M. (2005). La formación permanente del profesorado ante los nuevos retos del sistema educativo universitario. XI Congreso de Formación del profesorado, Segovia 17-19 de febrero.

Perrenoud, P. (2005). Dię nuevas competencias para enseñar. 3. ed. Graó.

Pinto, H. y Molina Puche, S. (2015). La educación patrimonial en los currículos de ciencias sociales en España y Portugal. Educatio Siglo XXI, 33(1), 103-128. https://doi.org/10.6018/j/222521

Piñeiro-Naval, V., Igartua, J.J. y Rodríguez-De-Dios, I. (2018). Implicaciones identitarias en la divulgación del patrimonio cultural a través de Internet: un estudio desde la Teoría del Framing. Communication \& Society, 31(1), 1-22.

Piñuel, J.L. (2002). Epistemología, Metodología y Técnicas del Análisis de Contenido. Estudios de Sociolinguïstica 3(1), $1-42$.

Sánchez-Macías, I. y Jorrín-Abellán, I. (2017). Estudio de caso sobre la evaluación por competencias en Educación Artística: Aportaciones a la Educación Patrimonial. Estudios pedagógicos (V aldivia), 43(4), 229250. https://dx.doi.org/10.4067/S0718-07052017000400012 
Simons, H. (2011). El Estudio de Caso: Teoría y práctica. Morata.

Solé, J. (2020). El cambio educativo ante la innovación tecnológica, la pedagogía de las competencias y el discurso de la educación emocional. Una mirada crítica. Teoría de la educación, 32(1), 101-121. $10.14201 /$ teri.20945

Tammaro, A. M (2017) New Profiles, New Skills, New Education for Digital Heritage Professionals: European Spotlight on Competency-Based System. International Information \& Library Review, 49(4), 290296. 10.1080/10572317.2017.1383748

Tejada, J. (2009). Competencias docentes. Profesorado. Revista de currículum y formación del profesorado, 13(2), 115.

Valcárcel, M. (2005) (Coord.). La preparación del profesorado universitario para la convergencia europea en educación superior. Informe Investigación, Proyecto EA2003-0040.

Zabalza, M. A. (2003). Competencias docentes del profesorado universitario. Calidad y desarrollo profesional. Narcea. 